\title{
Black Swiss Mouse
}

National Cancer Institute

\section{Source}

National Cancer Institute. Black Swiss Mouse. NCI Thesaurus. Code C122234.

Developed by Dr. Carl Hansen at the NIH, this strain was derived from a cross between NIH Swiss and C57BL/6N mice. The Black Swiss mouse has genotype Tyrp1B, (a) and is homozygous for the rd1 mutation of the Pde6b gene. 